\title{
Ursolic Acid Inhibits Proliferation and Induces Apoptosis of Cancer Cells In Vitro and In Vivo
}

\author{
Xuemei Wang, ${ }^{1}$ Fan Zhang, ${ }^{2}$ Ling Yang, ${ }^{2}$ Ying Mei, ${ }^{2}$ Hai Long, ${ }^{2}$ Xiaowen Zhang, ${ }^{3}$ \\ Jialing Zhang, ${ }^{2}$ Qimuge-Suyila, ${ }^{2}$ and Xiulan $\mathrm{Su}^{2}$ \\ ${ }^{1}$ PET-CT Center, The Affiliated Hospital of Inner Mongolia Medical College, TongDao North Street, Hohhot 010050, China \\ ${ }^{2}$ Clinical Medical Research Center of the Affiliated Hospital, Inner Mongolia Medical College, TongDao North Street, \\ Hohhot 010050, China \\ ${ }^{3}$ Department of Medical Education, The Affiliated People's Hospital of Inner Mongolia Medical College, Zhaoruda Street, \\ Hohhot 010010, China
}

Correspondence should be addressed to Xiulan Su, xlsu@hotmail.com

Received 30 December 2010; Revised 22 March 2011; Accepted 4 April 2011

Academic Editor: David J. Yang

Copyright () 2011 Xuemei Wang et al. This is an open access article distributed under the Creative Commons Attribution License, which permits unrestricted use, distribution, and reproduction in any medium, provided the original work is properly cited.

\begin{abstract}
The aims of the study are to explore the effect of ursolic acid (UA) on the growth of gastric cancer cell line BGC-803 and hepatocellular cancer cell H22 xenograft and to understand the mechanism. UA inhibits growth of BGC-803 cells in vitro in dose-dependent and time-dependent manner. Treated with UA in vivo, tumor cells can be arrested to G0/G1 stage. The apoptotic rate was significantly increased in tumor cells treated with UA both in vitro and in vivo. DNA fragmentation was found in BGC-803 cells exposed to UA. UA activated caspase-3, -8 , and -9 and down regulated expression of Bcl-2 in BGC-803 cells. The expression of caspase-3 and -8 was elevated in tumor cells from xenograft treated with UA. ${ }^{18}$ F-FLT PET-CT imaging confirmed tumor model and UA effectiveness. Our results indicated that UA inhibits growth of tumor cells both in vitro and in vivo by decreasing proliferation of cells and inducing apoptosis.
\end{abstract}

\section{Introduction}

Gastric cancer is the second cause of cancer-related death worldwide, and it has now become the first cancer-related death in China. Hepatocellular carcinoma is a primary ma-lignancy of the liver and is the third leading cause of cancer-related death worldwide. There are about 110,000 people died of gastric cancer and hepatocellular carcinoma in China every year, which accounts for $45 \%$ (for both cancer combined) mortality worldwide. In addition to surgery, radiotherapy, and chemotherapy, it is essential to find a more effective way to treat gastric cancer and hepatocellular carcinoma.

More and more clinical practice shows that the Chinese medicinal herbs have antitumor activity, which sheds a light on new therapeutic strategy for cancer treatment [1-3]. Ursolic acid (UA) is a pentacyclic triterpene compound and exists in medicinal herbs such as Oldenlandia diffusa and Radix actinidiae. UA has been shown to have the effects of anti-inflammatory, antioxidant, and antitumor [4-6]. Studies have found that UA can inhibit the activities of DNA polymerase and DNA topoisomerase and decrease the rate of cell proliferation [7]. Moreover, UA can induce apoptosis of tumor cell by increasing the level of intracellular calcium ion [8], suppressing the expression of FoxM1 [9], and upregulating of death receptors [10]. In this study, we evaluated the effect of UA treatment on the gastric cancer cell and the hepatocellular carcinoma xenograft.

\section{Materials and Methods}

2.1. Material. UA was purchased from Shanxi Huike Plant Development Corporation (UR: 20030610 purity $\geq 98 \%$ ). 3-(4,5-dimethylthiazol-2-yl)-2,5-diphenyltetrazolium bromide (MTT) and DMSO were purchased from SIGMA Company. Annexin-V-FITC apoptosis kit was purchased from BD Biosciences. RPMI 1640 and calf serum was purchased from GIBCO, Invitorgen. All the antibodies used in 
western blot (rabbit antihuman $\beta$-actin, mouse antihuman procaspase-3, mouse antihuman procaspase- 8 , mouse antihuman procaspase- 9 , mouse antihuman $\mathrm{Bcl}-2$, and mouse antihuman Bax antibodies) were purchased from SANTA CRUZ Biotechnology. Far infrared-marked goat antirabbit or mouse secondary antibodies were purchased from ROCKLAND Immunochemicals. Odyssey far infrared scanner was purchased from LI-COR Biosciences (USA).

2.2. Cell Lines and Culture Conditions. BGC-803 cell and hepatocellular carcinoma cell line H22 (ATCC, USA) were generous gifts from Dr. Yang Ke at the Cancer Research Center, Peking University. Gastric cancer cell line BGC-803 was maintained in RPMI-1640 with 10\% calf serum. Cells were grown at $37^{\circ} \mathrm{C}$ in a $\mathrm{CO}_{2}$ incubator. The cells in the exponential growth phase were collected for cell proliferation, cell cycle, and apoptosis assay.

2.3. Mouse Model. Ten male and ten female kunming mice were bought from The Research Center for Laboratory Animal Science in Beijing, and $\mathrm{H} 22$ cells of exponential growth phase were injected subcutaneously into right front axilla of kuming mice. The mice were divided into two groups with equal numbers of male and female mice. One group was given $0.2 \mathrm{~mL} /$ mouse physiological saline by oral administration as negative control; another group was given $2.53 \mathrm{mg} / \mathrm{mouse}$ UA everyday for 10 days. Mice were sacrificed at the end of the treatment. Tumors tissues were either fixed in 75 ethanol filtered after treated by 500 mesh to get the single cell suspension for flow cytometry analysis or fixed in $4 \%$ paraformaldehyde for pathological analysis. Samples prepared from tumor tissues were also flash frozen in liquid nitrogen for Western blot analysis. All animal experiments were approved by Animal Care and Use Committee, Inner Mongolia Medical College.

2.4. Cell Proliferation Assay. Cell proliferation was assessed by MTT staining. $250 \mu \mathrm{L}$ of BGC-803 cells $\left(1.2 \times 10^{4} / \mathrm{mL}\right)$ were added to each well in the 96 -well plate. UA was added to the final concentration of $10-60 \mu \mathrm{M}$. DMSO and culture medium were added as control. Each group was performed in 8 wells. MTT was added $12 \mathrm{~h}, 24 \mathrm{~h}, 36 \mathrm{~h}$, and $48 \mathrm{~h}$, respectively, after incubation, and the absorbance values were examined. The inhibiting proliferation rates were calculated using the following equation:

Inhibiting proliferation rate $(\%)$

$$
=\frac{(\text { A values of control group }- \text { A values of treated group })}{\text { A values of control group }}
$$$$
\times 100 \% \text {. }
$$

2.5. ${ }^{18}$ F-FLT PET-CT Imaging. Proliferation of tumor cells in mouse xenograft model was examined with positron-emission tomography-computed tomography (PET-CT) using ${ }^{18} \mathrm{~F}$ fluoro-L-thymidine (FLT). ${ }^{18} \mathrm{~F}$-FLT was given to the mouse by tail intravenous injection. Mice were anesthetized by ether and then were imaged by PET-CT.

2.6. Cell Cycle and Apoptosis Assay. BGC-803 cells were treated with UA either at concentration of median inhibition concentration $\left(\mathrm{IC}_{50}\right)(24 \mathrm{~h})$ for $24 \mathrm{~h}$, or at concentration of $\mathrm{IC}_{50}(36 \mathrm{~h})$ for $36 \mathrm{~h}$, and then cells were fixed in $75 \%$ ethanol. Tumor cells obtained from xenograft were also fixed in $75 \%$ ethanol after filtered by 500 mesh. The single-cell suspension obtained above was used for apoptosis analysis using flow cytometry and for cell cycle analysis using ModFit analysis. DNA was extracted from BGC-803 cells according to protocol provided by manufacturer and then isolated in the $1.5 \%$ agarose gel by electrophoresis $(65 \mathrm{~V}, 1.75 \mathrm{~h})$. Photographs were taken using a gel-imaging system to detect DNA Ladder.

2.7. Western Blot Analysis. Expression of procaspase-3, -8, and $-9, \mathrm{Bcl}-2$, and Bax in BGC-803 treated with UA for $36 \mathrm{~h}$ at $\mathrm{IC}_{50}$ and expression of caspase- 3 and -8 in tumor cells obtained from xenograft was determined by western blot. Cells were treated with RIPA buffer ( $1 \%$ deoxycholate, $0.1 \%$ SDS). Concentration of protein was determined by BCA assay. Proteins were transferred to PVDF membrane after separation by SDS-PAGE and incubated with proper primary and secondary antibodies. The signal was detected by far infrared scanner. Result was analyzed by Quantity One. The relative amount of protein expressed was determined by using $\beta$-actin as an internal control.

2.8. Statistical Analysis. Statistical analysis was performed using the program SPSS13.0. In each experimental group, one-factor analysis of variance and MANOVA of repeated measuring were used. The $t$-test was used for comparison between groups. A value of $P<.05$ was considered to be statistically significant. $\mathrm{IC}_{50}$ values at different time points were calculated by Probit Analysis.

\section{Results}

3.1. Inhibition of Proliferation in BGC-803 Cells. Proliferation of BGC-803 cells was examined to assess whether UA had inhibitory effect on BGC-803. Cells were treated with different concentrations of UA $(10,20,30,40,50,60 \mu \mathrm{mol} / \mathrm{L})$ for $12,24,36,48 \mathrm{~h}$, respectively. Compared with control, UA $(20-60 \mu \mathrm{mol} / \mathrm{L})$ inhibited BGC-803 cell proliferation in dose- and time-dependent manners. However, $10 \mu \mathrm{mol} / \mathrm{L}$ of UA did not show inhibitory effect (Figure $1(\mathrm{a})$ ). The $\mathrm{IC}_{50}$ of $\mathrm{UA}$ at different time points $(12 \mathrm{~h}, 24 \mathrm{~h}, 36 \mathrm{~h}$ and $48 \mathrm{~h}$ ) were $61.29 \mu \mathrm{M}, 43.78 \mu \mathrm{M}, 35.94 \mu \mathrm{M}$, and $24.95 \mu \mathrm{M}$, respectively (Table 1).

3.2. Induction of Apoptosis in BGC-803 Cells. Morphological changes of BGC-803 cells after UA treatment. Cells not treated with UA showed single-layer adherence growth with rich cytoplasm, round or oval nuclei. Cells exposed to UA rounded up, lacked cell-cell contact with low density of cell (Figure 1(b)). Furthermore, H\&E staining revealed 
TABLE 1: $\mathrm{IC}_{50}$ of UA at different time points in human gastric cancer cell BGC-803.

\begin{tabular}{ccccc}
\hline & $\mathrm{IC}_{50}(\mathrm{uM})$ & $X^{2}$ & $P$ & Probit \\
\hline $12 \mathrm{~h}$ & 61.29 & 0.005 & 1.0 & $7.60-13.5 \mathrm{x}$ \\
$24 \mathrm{~h}$ & 43.78 & 0.027 & 1.0 & $5.49-9.01 \mathrm{x}$ \\
$36 \mathrm{~h}$ & 35.94 & 0.07 & 0.99 & $3.08-4.79 \mathrm{x}$ \\
$48 \mathrm{~h}$ & 24.95 & 0.018 & 1.0 & $5.74-8.08 \mathrm{x}$ \\
\hline
\end{tabular}

that cells treated with UA showed typical morphology for apoptosis: nuclear fragmentation, chromatin condensation, and loss of membrane asymmetry (Figure 1(c)). In addition, fragments of degraded DNA were observed in agarose gel electrophoresis for BGC-803 cells treated with 43.78 and $35.94 \mu \mathrm{M}$ UA. This was an indication that apoptosis occurred in the cells. For the control cells without treatment, no fragment of DNA was observed (Figure 1(d)). We further evaluated the apoptotic rate by Annexin-V staining. BGC803 cells treated with UA had more apoptotic cells than cells treated with DMSO or without treatment $(F=72.579$, $P<.01$, Figures $1(\mathrm{e})$ and $1(\mathrm{f})$ ), while there was no significant difference in apoptosis between cells treated with DMSO or without treatment indicating that apoptosis was specifically induced by UA treatment.

We investigated the mechanism how UA induced apoptosis. Expression of Pro caspase-3, -8, and -9, Bcl-2, Bax was detected by Western blot (Figure $1(\mathrm{~g})$ ). Relative amount of protein was calculated (Figure 1(h)). Our data showed that expression of pro caspase- $3,-8$, and -9 protein declined after UA treatment $(P<.05)$, indicating that activated caspase-3, $-8,-9$ proteins were induced by UA treatment. Expression of Bcl-2 protein was downregulated by UA treatment $(P<.05)$, while Bax protein expression did not show significant change with and without UA treatment. Our result suggested that UA may activate caspase cascade and downregulate Bcl-2 protein to induce apoptosis in gastric cancer cell line BGC803.

3.3. Inhibition of Tumor Growth in Mouse Xenograft Model. Compared to negative control, xenografts which were treated with UA were robust and had more weight (Table 2). There was $52.8 \%$ inhibition rate of tumor growth in UA treatment xenografts. Tumor tissue was examined under optical microscope after H\&E staining. Tumor cells in negative control resembled nests or cords and showed vigorous mitosis. Nuclei of tumor cells were round or oval; while there was more necrosis and apoptosis in UA treatment group, density of tumor cells decreased. We examined the proliferation of tumor cells in xenografts by PET-CT. Xenografts was injected with ${ }^{18} \mathrm{~F}$-FLT, and the whole mouse was imaged by PETCT. Focal ${ }^{18}$ F-FLT uptake could be observed in tumor and abdominal cavity in xenografts of PS control (Figure 2(a) upper panel). Xenografts with UA treatment showed lower ${ }^{18}$ F-FLT uptake in tumor (Figure 2(a) lower panel). The image of PET-CT showed directly that proliferation of tumor cells declined by UA treatment in vivo. To elucidate the mechanism how UA inhibited proliferation of tumor cells, we examined cell cycle of these tumor cells in xenografts.
Percentange of $38.71 \pm 3.27$ of the tumor cells treated with UA were in G0/G1 stage $(P<.05$, Figure $2(\mathrm{~b}))$, but $48.97 \pm 3.96 \%$ and $23.53 \pm 5.97 \%$ cells were in S or G2/M stage for the negative control, suggesting that UA treatment decreased proliferation of tumor cells in mouse xenograft model.

3.4. Induction of Apoptosis in Mouse Xenograft Model. In addition to cell cycle, we also examined the apoptosis of tumor cells in xenografts. Tumor cells in xenografts treated with UA had more apoptosis as shown in Figure 2(b) (subG1). The apoptotic tumor cells were quantified by flow cytometry after cells were incubated with FITC conjugated Annexin-V. Comparison of apoptotic rate of the PS control to the UA treatment group revealed statistically significant different $(12.91 \pm 1.43$ for PS control versus $37.24 \pm 3.85$ for UA treatment, $P<.05$, Figure $2(\mathrm{c})$ ), indicating that UA treatment could induce apoptosis of tumor cells in mouse xenograft model. Furthermore, we examined the expression of Caspase- $3,-8$ in these tumor cells. The result of western blot showed that the protein level of Caspase$3,-8$ was elevated after treatment with UA (Figure 2(d)). Our data suggested that UA may induce apoptosis through upregulation of Caspase- 3 and 8.

\section{Discussion}

UA is one anticancer active compound in Chinese anticancer herbal medicines. Previous studies showed that UA could inhibit growth of colon cancer cells, endometrial cancer cells, and melanoma cells [11-13]. It has been reported that UA inhibited growth of tumor cells through multiple functions, such as cytotoxicity $[14,15]$, induction of apoptosis $[9,10$, $16,17]$, and prevention of angiogenesis $[18,19]$.

Our results showed that UA decreased proliferation of tumor cells both in vitro and in vivo. UA inhibited proliferation of BGC-803 cells in dose- and time-dependent manners. Inhibition rate of tumor growth is $52.8 \%$ in $\mathrm{H} 22$ xenografts treated with UA. Cell cycle of tumor cells from xenagrafts treated with UA was arrested in G0/G1 stage. Our data are consistent with the results of lung cancer cell A549 treated with UA [20], Hsu showed that UA up-regulated P21 expression through a P53-dependent manner and decreased expression of cyclins and their activating partner cdks. UA may block cell cycle progression in G0/G1 stage in gastric cancer cell and tumor cells from xenografts by activating P53/P21 pathway concomitant with inactivating cyclins/cdks.

Mammalian cell apoptosis is initiated either by mitochondria-mediated or Fas receptor coupled extrinsic signals mediated pathways. Many apoptotic-related genes involved in these processes, including proapoptotic genes (Bax, Bid, and Bak), antiapoptotic genes (Bcl-Xl and Bcl-2), and cysteine proteases called caspases (caspase-3, -8, and -9). Bcl2 family plays an important role in preventing apoptosis. The ratio of Bax to Bcl-2 can be used to assess apoptosis. The higher this ratio is, the more possibility apoptosis would happen, and vice versa. We found that the expression of Bcl-2 protein decreased, but the level of Bax protein did 


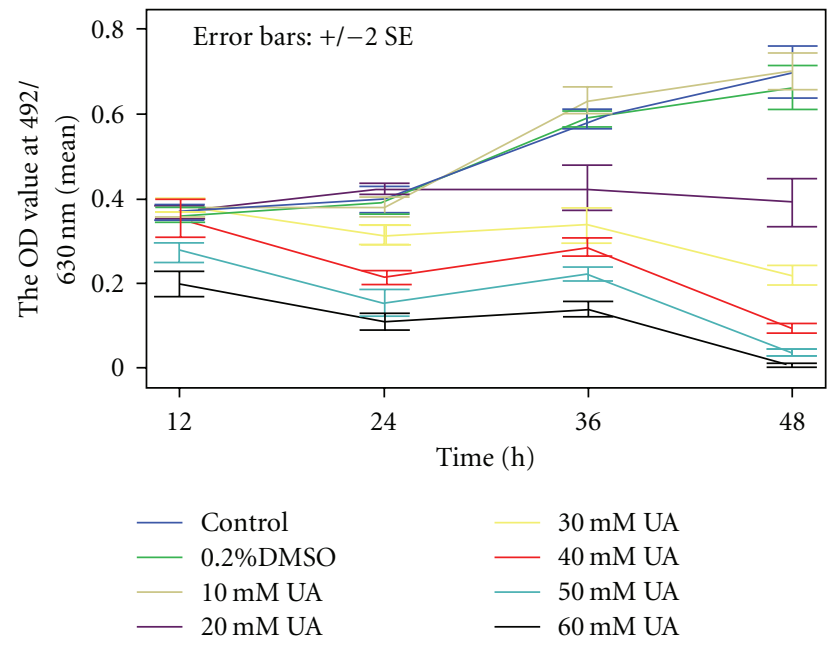

(a)
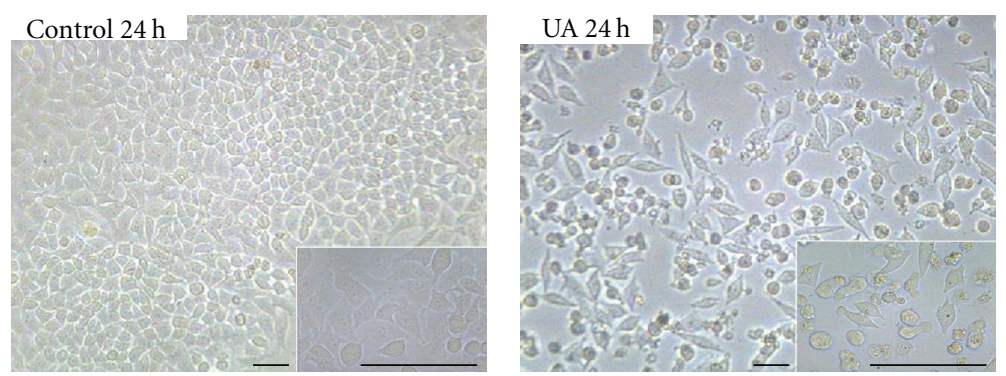

(b)
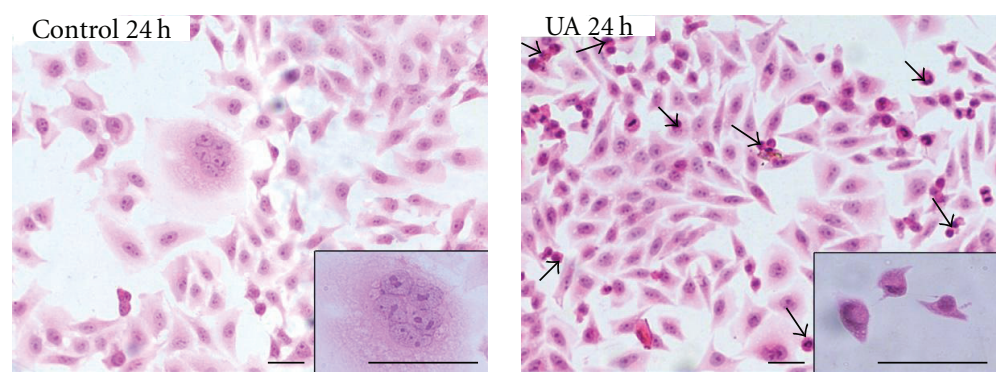

(c)
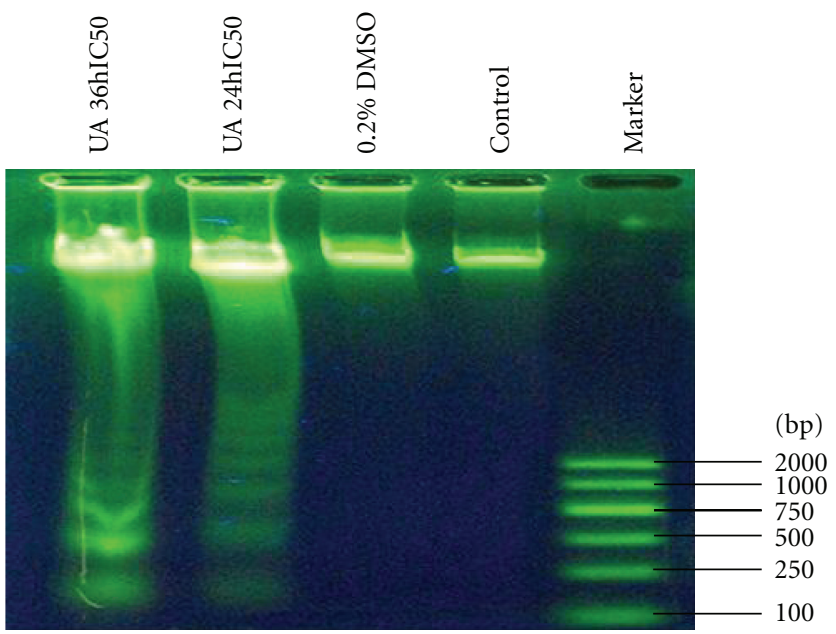

(d)

Figure 1: Continued. 

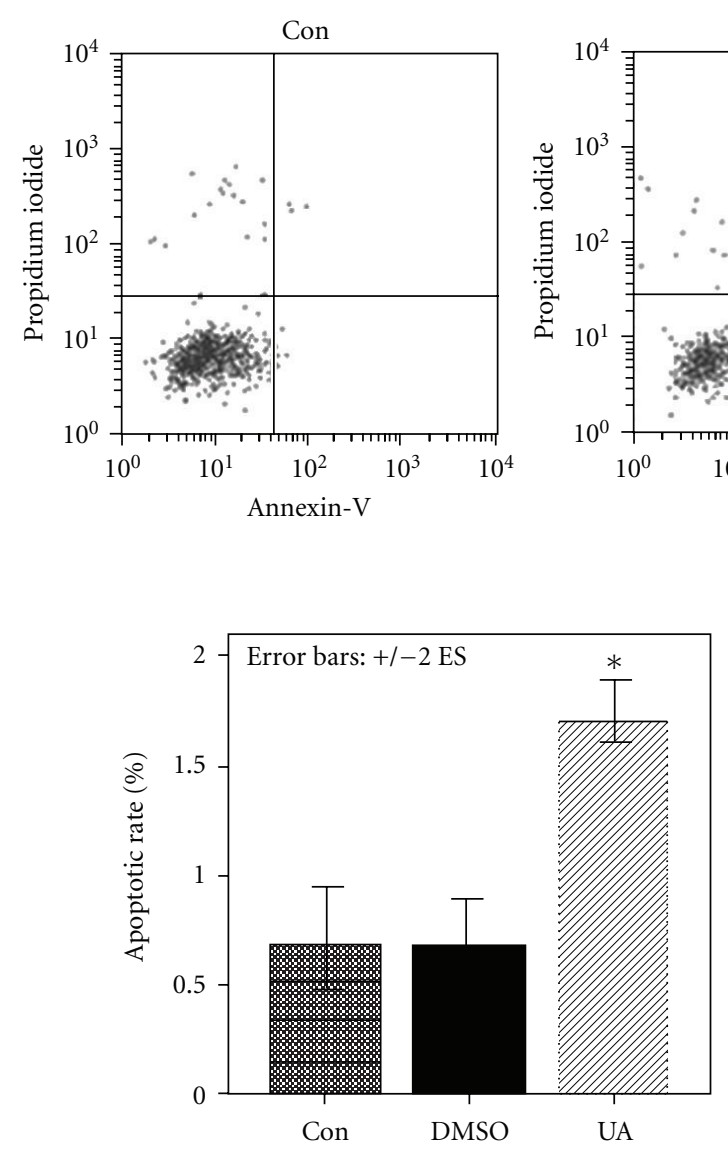

(f)
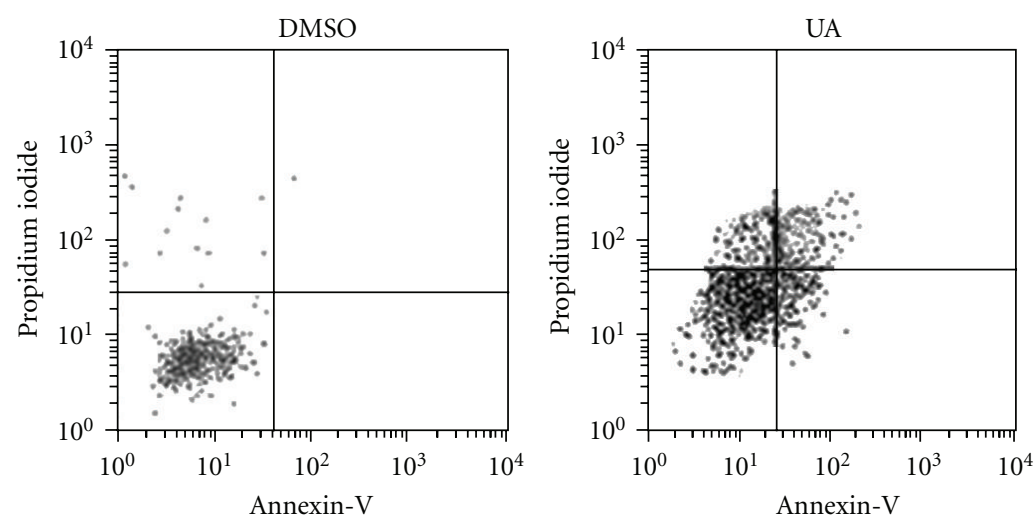

(e)

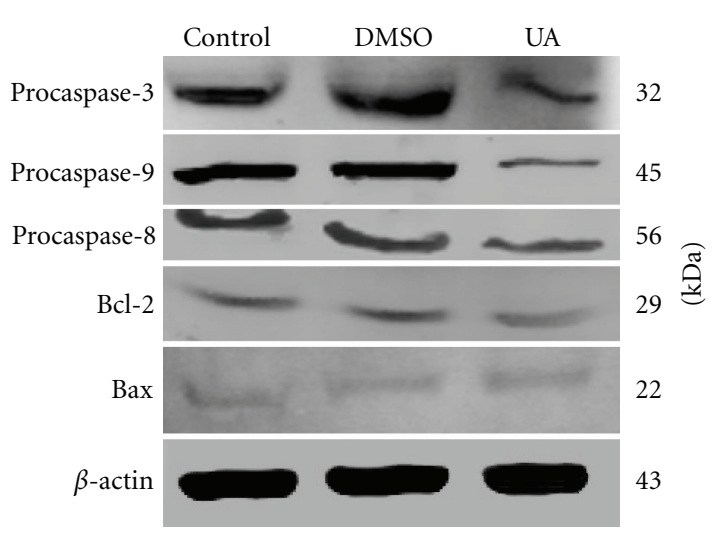

$(\mathrm{g})$

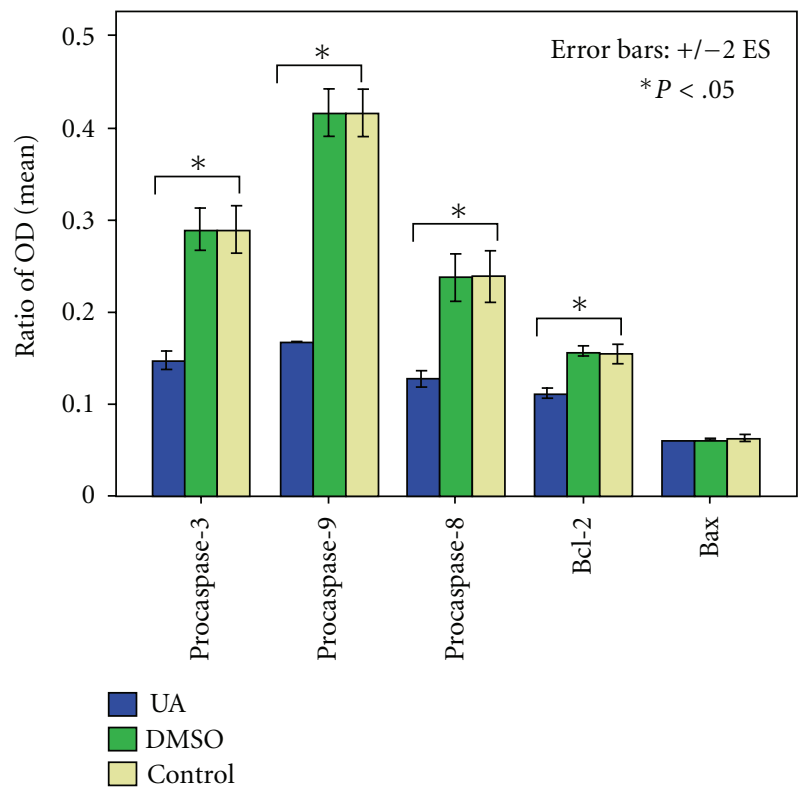

(h)

FIGURE 1: UA inhibited proliferation and induced apoptosis in gastric cancer cell BGC-803. (a) Inhibition of proliferation of BGC-803 was assessed by MMT staining. (b) Morphological changes of BGC-803 cells after UA ( $\mathrm{IC}_{50}(24 \mathrm{~h})$ ) treatment for $24 \mathrm{~h}$ (Bar represents $200 \mu \mathrm{m}$ ); magnified image of cells was showed in corner (Bar represents $200 \mu \mathrm{m}$ ). (c) H\&E staining of BGC-803 cells after UA (IC 50 (24 h)) treatment for $24 \mathrm{~h}$ (Bar represents $200 \mu \mathrm{m}$ ), and arrows indicated apoptotic cells; magnified image of cells was showed in corner (Bar represents $200 \mu \mathrm{m})$. (d) DNA ladder was found in BGC-803 cells treated with UA (IC $50(24 \mathrm{~h})$ and $\mathrm{IC}_{50}(36 \mathrm{~h})$ ), not in BGC-803 cells treated with $0.2 \%$ DMSO or without treatment. (e) Apoptosis of BGC-803 cells induced by UA was detected by Annexin-V staining and flow cytometry. (f) was the quantified data from experiment showed in (e). Apoptotic rate was $0.66 \pm 0.15,0.67 \pm 0.08$, and $1.69 \pm 0.11$ in control, DMSO, and UA treated cells, respectively, $\left({ }^{*} P<.01\right)$. (g) Western blot showed expression of apoptotic related genes in BGC-803 cell treated with DMSO, UA and without treatment; $\beta$-actin was used as internal control. (h) showed related amount of protein from $(\mathrm{g})\left({ }^{*} P<.05\right)$. 


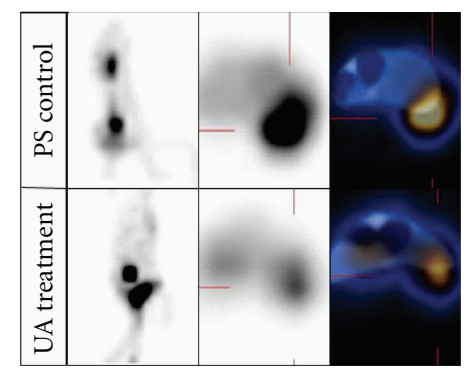

(a)

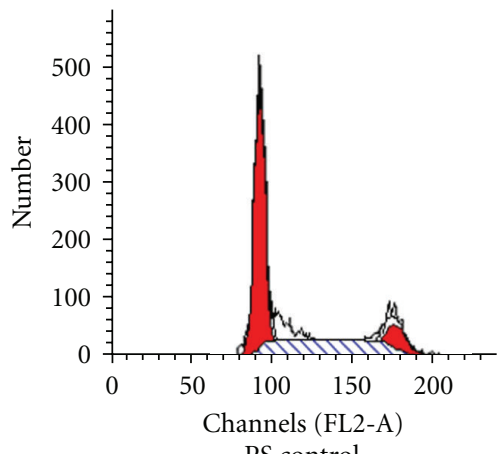

PS control

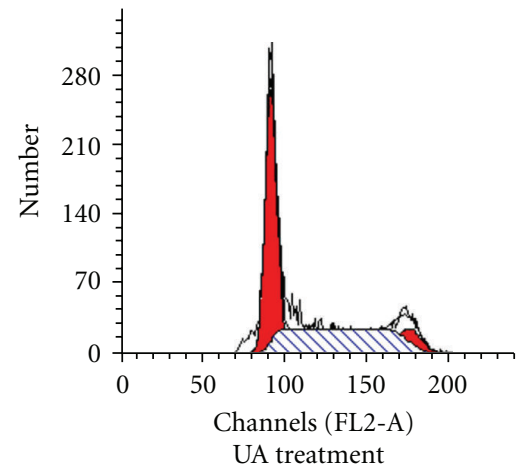

\begin{tabular}{|c|c|c|c|}
\hline \multirow{2}{*}{} & \multicolumn{3}{|c|}{ Cell cycle distribution (\%) } \\
\cline { 2 - 4 } & G0/G1 & S & G2/M \\
\hline PS control & $21.5 \pm 2.82$ & $48.97 \pm 3.96$ & $23.53 \pm 5.97$ \\
\hline UA treatment & $38.71 \pm 3.27^{*}$ & $41.83 \pm 1.37^{*}$ & $19.4 \pm 1.91^{*}$ \\
\hline
\end{tabular}

(b)
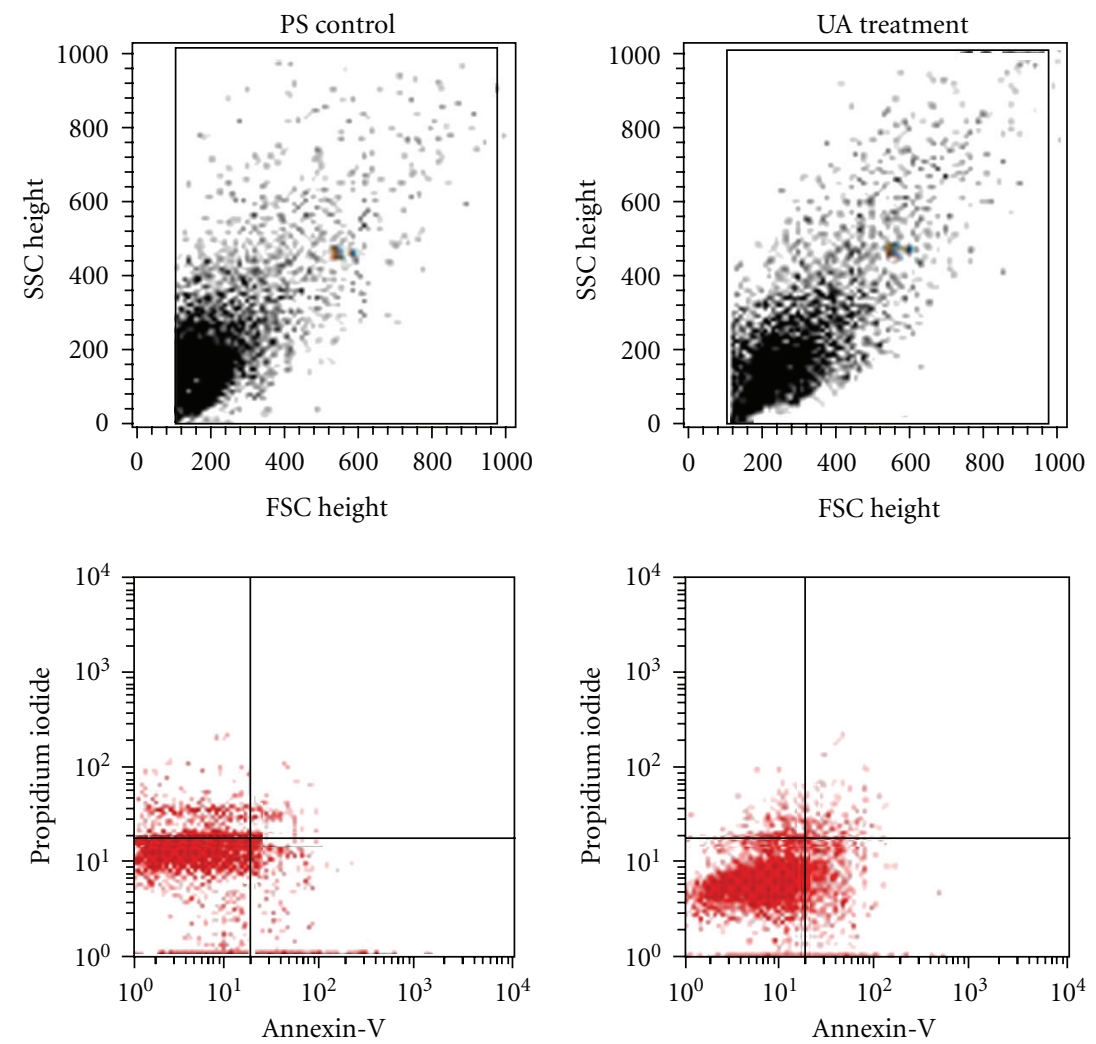

\begin{tabular}{|c|c|}
\hline & AI $(\mathrm{X} \% \pm \mathrm{S})$ \\
\hline PS control & $12.91 \pm 1.43$ \\
\hline UA treatment & $37.24 \pm 3.85^{*}$ \\
\hline
\end{tabular}

(c)

FIgURE 2: Continued. 


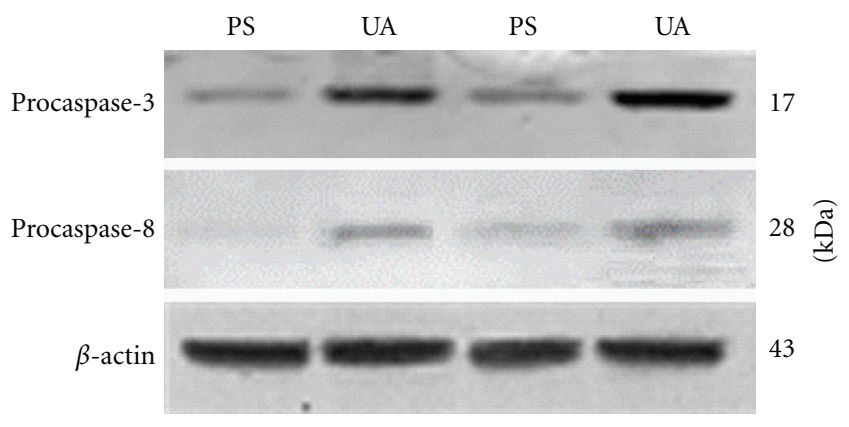

(d)

FIGURE 2: UA inhibited proliferation and induced apoptosis in hepatocellular carcinoma cell H22 mouse xenograft. (a) Xenografts treated with PS or UA were imaged by PET-CT. (b) Cell cycle of tumor cells from xenografts treated with PS or UA was examined. Cell cycle distribution was showed in the table $\left({ }^{*} P<.05\right)$. (c) Apoptosis of tumor cells from xenografts induced by UA was detected by Annexin-V staining and flow cytometry. Quantified data showed in the table below $\left({ }^{*} P<.05\right)$. (d) Western blot showed expression of Caspase-3 and Caspase-8 in tumor cells from xenografts treated with PS or UA.

TABLE 2: Weight of xenografts treated with PS or UA.

\begin{tabular}{lcccccc}
\hline & Day 1 & Day 3 & Day 5 & Day 7 & Day 9 & Day 11 \\
\hline PS control $(\mathrm{g})$ & $22.04 \pm 0.73$ & $23.93 \pm 0.83$ & $25.41 \pm 0.65$ & $27.46 \pm 1.35$ & $29.51 \pm 1.47$ & $30.05 \pm 1.51$ \\
UA treatment $(\mathrm{g})$ & $21.88 \pm 0.57$ & $24.85 \pm 0.53$ & $27.17 \pm 0.89$ & $29.39 \pm 1.62$ & $31.66 \pm 2.43$ & $32.68 \pm 2.65$ \\
\hline
\end{tabular}

not change in BGC-803 cells treated with UA. The ratio of $\mathrm{Bax} / \mathrm{Bcl}-2$ increased, which would lead to apoptosis. Previous studies showed that Bax expression increased and Bcl-2 expression decreased in lung cancer cell line A549 treated with UA [20]. Expression of Bax protein significantly increased in human breast cancer cell line MCF-7 [21]. The results above are different from ours, suggesting that UA may function differently in different type of cancer cells to induce apoptosis. Caspase- 3 is a key protease in mammalian cell apoptosis. We found that caspase- 3 was activated in BGC-803 cells and H22 cell xenograft treated with UA. It is reported that cytochrome $\mathrm{C}$ was released and caspase- 3 was activated in BGC-823 cells with UA treatment [22]. Our data showed that caspase- 8 and -9 were all activated in BGC803 cells, indicating that UA induced apoptosis through two classical apoptotic pathways. Studies have demonstrated that caspase-3, -8 , and -9 are necessary for UA inducing tumor cell apoptosis [23]. Our findings of decreased level of Bcl-2 with no change of Bax and activated caspase- 8 and -9 in cell line BGC-803 enrich the understanding of mechanisms how UA induces apoptosis in gastric cancer cell line BGC- 803 . Furthermore, we found expression of caspase- 8 was elevated in tumor cells obtained from $\mathrm{H} 22$ xenograft, indicating that UA also can induce apoptosis in vivo.

\section{Conclusions}

In summary, we found that UA inhibited growth of gastric cancer cell line BGC-803 in dose-dependent and timedependent manner in vitro. UA treatment arrested tumor cells from xenograft to G0/G1 stage in vivo. The apoptotic rate was significantly increased in tumor cells treated with UA both in vitro and in vivo $(P<.05)$. DNA fragmentation was found in BGC-803 cells exposed to UA. UA activated caspase-3, $-8,-9$ and downregulated expression of $\mathrm{Bcl}-2$ in BGC-803 cells, but had no effect on expression of Bax. Expression of caspase- 3 and -8 were elevated in tumor cells from xenograft treated with UA. UA inhibited growth of tumor cells in vitro and vivo by decreasing proliferation and inducing apoptosis. Understanding the mechanism of UA will help us fully understand how Chinese medical herbs work.

\section{Conflict of Interests}

The authors declare that they have no conflict of interests.

\section{Acknowledgments}

The authors' research is supported by the Autonomous Region Natural Science Foundation of China, no. 200711020906. They are grateful that Dr. Yang Ke generously gives them gastric cell line BGC-803 and hepatocellular carcinoma cell line H22. X. Wang and F. Zhang contributed equally to this work.

\section{References}

[1] Y. Xiao, Y. Fan, B. Chen, Q. Zhang, and H. Zeng, "Polysaccharides from Scurrula parasitica L. inhibit sarcoma S180 growth in mice," Zhongguo Zhongyao Zazhi, vol. 35, no. 3, pp. 381384, 2010.

[2] T. Gan, Z. Wu, L. Tian, and Y. Wang, "Chinese herbal medicines for induction of remission in advanced or late gastric cancer," Cochrane Database of Systematic Reviews, no. 1, Article ID CD005096, 2010. 
[3] Z. G. Zhong, J. L. Huang, H. Liang et al., "The effect of gallic acid extracted from leaves of Phyllanthus emblica on apoptosis of human hepatocellular carcinoma BEL-7404 cells," Zhong Yao Cai, vol. 32, no. 7, pp. 1097-1101, 2009.

[4] N. Banno, T. Akihisa, H. Tokuda et al., "Triterpene acids from the leaves of Perilla frutescens and their anti-inflammatory and antitumor-promoting effects," Bioscience, Biotechnology and Biochemistry, vol. 68, no. 1, pp. 85-90, 2004.

[5] R. E. De Angel, S. M. Smith, R. D. Glickman, S. N. Perkins, and S. D. Hursting, "Antitumor effects of ursolic acid in a mouse model of postmenopausal breast cancer," Nutrition and Cancer, vol. 62, no. 8, pp. 1074-1086, 2010.

[6] A. A. Ramos, C. Pereira-Wilson, and A. R. Collins, "Protective effects of ursolic acid and luteolin against oxidative DNA damage include enhancement of DNA repair in Caco-2 cells," Mutation Research, vol. 692, no. 1-2, pp. 6-11, 2010.

[7] Y. Mizushina, A. Iida, K. Ohta, F. Sugawara, and K. Sakaguchi, "Novel triterpenoids inhibit both DNA polymerase and DNA topoisomerase," Biochemical Journal, vol. 350, no. 3, pp. 757763, 2000.

[8] F. Lauthier, L. Taillet, P. Trouillas, C. Delage, and A. Simon, "Ursolic acid triggers calcium-dependent apoptosis in human Daudi cells," Anti-Cancer Drugs, vol. 11, no. 9, pp. 737-745, 2000.

[9] J. S. Wang, T. N. Ren, and T. Xi, "Ursolic acid induces apoptosis by suppressing the expression of FoxM1 in MCF-7 human breast cancer cells," Medical Oncology, 2010. In press.

[10] S. Prasad, V. R. Yadav, R. Kannappan, and B. B. Aggarwal, "Ursolic acid, a pentacyclin triterpene, potentiates TRAILinduced apoptosis through p53-independent up-regulation of death receptors: evidence for the role of reactive oxygen species and JNK," The Journal of Biological Chemistry, vol. 286, no. 7, pp. 5546-5557, 2011.

[11] Y. Achiwa, K. Hasegawa, T. Komiya, and Y. Udagawa, "Ursolic acid induces Bax-dependent apoptosis through the caspase3 pathway in endometrial cancer SNG-II cells," Oncology Reports, vol. 13, no. 1, pp. 51-57, 2005.

[12] D. Andersson, J. J. Liu, A. Nilsson, and R. D. Duan, "Ursolic acid inhibits proliferation and stimulates apoptosis in HT29 cells following activation of alkaline sphingomyelinase," Anticancer Research, vol. 23, no. 4, pp. 3317-3322, 2003.

[13] P. O. Harmand, R. Duval, C. Delage, and A. Simon, "Ursolic acid induces apoptosis through mitochondrial intrinsic pathway and caspase- 3 activation in M4Beu melanoma cells," International Journal of Cancer, vol. 114, no. 1, pp. 1-11, 2005.

[14] K. H. Lee, Y. M. Lin, T. S. Wu et al., "The cytotoxic principles of Prunella vulgaris, Psychotria serpens, and Hyptis capitata: ursolic acid and related derivatives," Planta Medica, vol. 54, no. 4, pp. 308-311, 1988.

[15] M. Ganblod, J. Barker, R. Ma, L. Jones, and M. Carew, "Cytotoxicity and bioavailability studies on a decoction of Oldenlandia diffusa and its fractions separated by HPLC," Journal of Ethnopharmacology, vol. 131, no. 2, pp. 396-403, 2010.

[16] J. Li, W. J. Guo, and Q. Y. Yang, "Effects of ursolic acid and oleanolic acid on human colon carcinoma cell line HCT15," World Journal of Gastroenterology, vol. 8, no. 3, pp. 493-495, 2002.

[17] W. Huang, J. Huang, D. Zhang, R. Zhang, and Z. Liao, "Study on anti-invasive effect and apoptosis induction of pentacyclic triterpenoid in human lung cancer cells," Chinese Journal of Lung Cancer, vol. 6, no. 4, pp. 254-257, 2003.

[18] M. Kanjoormana and G. Kuttan, "Antiangiogenic activity of ursolic acid," Integrative Cancer Therapies, vol. 9, no. 2, pp. 224-235, 2010.
[19] C. C. Lin, C. Y. Huang, M. C. Mong, C. Y. Chan, and M. C. Yin, "Antiangiogenic potential of three triterpenic acids in human liver cancer cells," Journal of Agricultural and Food Chemistry, vol. 59, no. 2, pp. 755-762, 2011.

[20] Y. L. Hsu, P. L. Kuo, and C. C. Lin, "Proliferative inhibition, cell-cycle dysregulation, and induction of apoptosis by ursolic acid in human non-small cell lung cancer A549 cells," Life Sciences, vol. 75, no. 19, pp. 2303-2316, 2004.

[21] W. Zhang, Y. Li, G. Zhang, J. Lü, and H. Ou, "Experimental study on MCF-7 cell apoptosis induced by ursolic acid," Zhong Yao Cai, vol. 28, no. 4, pp. 297-301, 2005.

[22] J. Zhang, T. Deng, and H. Chen, "Ursolic acid inhibits proliferation and induces apoptosis in human gastric carcinoma cell line BGC-823," Medical Journal of Wuhan University, vol. 26, no. 3, pp. 375-378, 2005.

[23] Y. H. Choi, J. H. Baek, M. A. Yoo, H. Y. Chung, N. D. Kim, and K. W. Kim, "Induction of apoptosis by ursolic acid through activation of caspases and down-regulation of c-IAPs in human prostate epithelial cells," International Journal of Oncology, vol. 17, no. 3, pp. 565-571, 2000. 


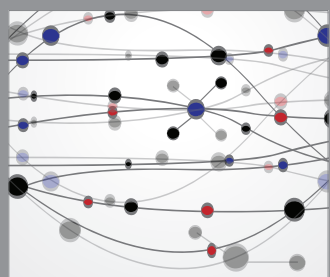

The Scientific World Journal
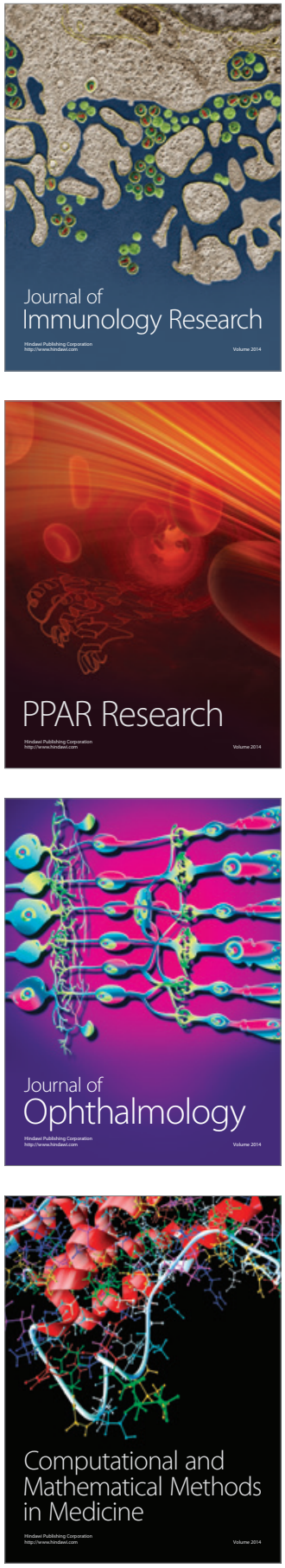

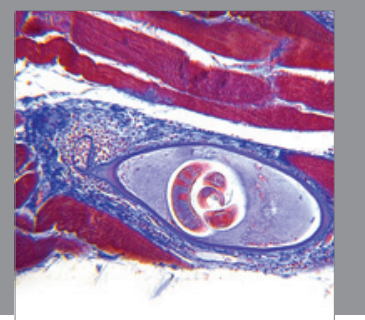

Gastroenterology

Research and Practice
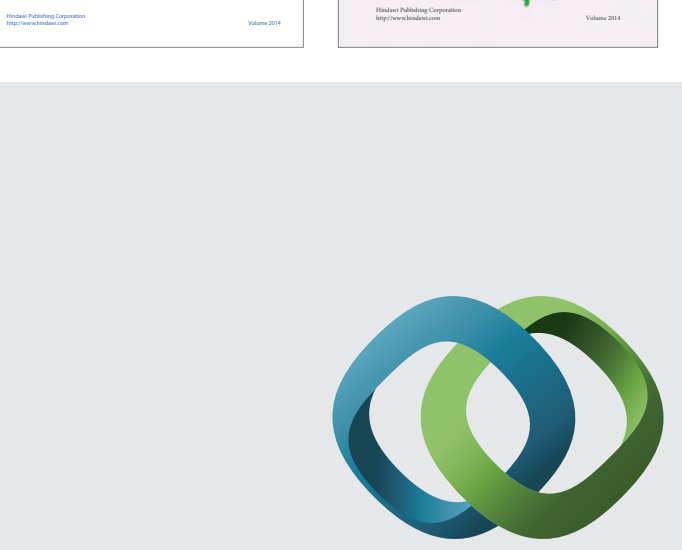

\section{Hindawi}

Submit your manuscripts at

http://www.hindawi.com
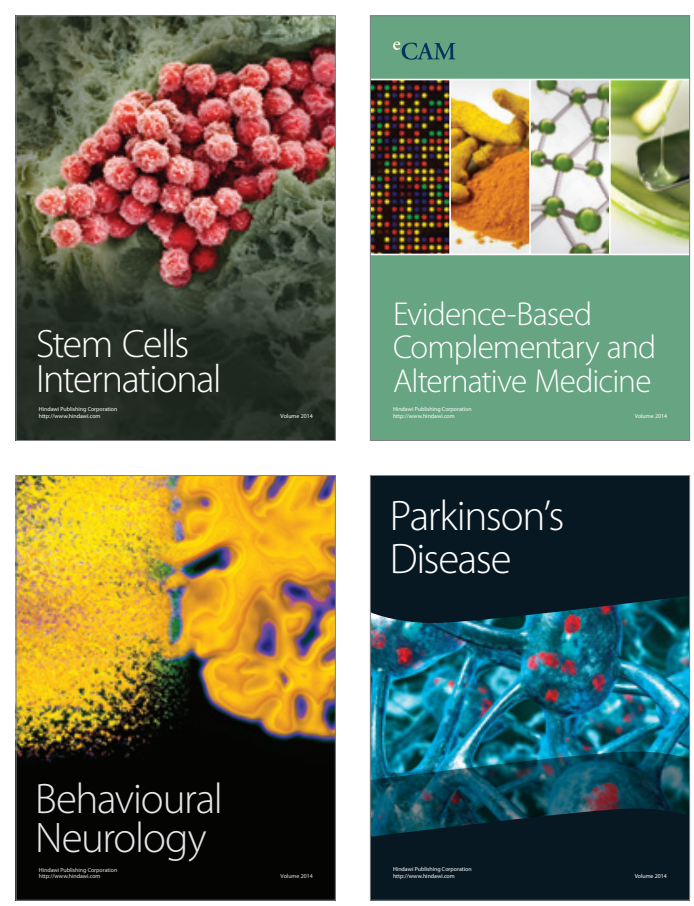

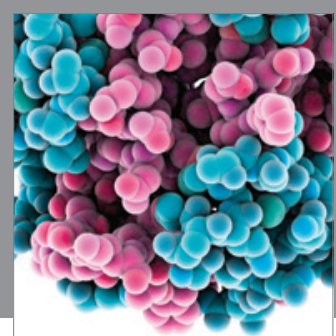

Journal of
Diabetes Research

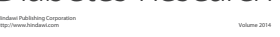

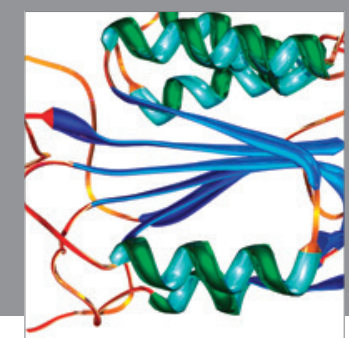

Disease Markers
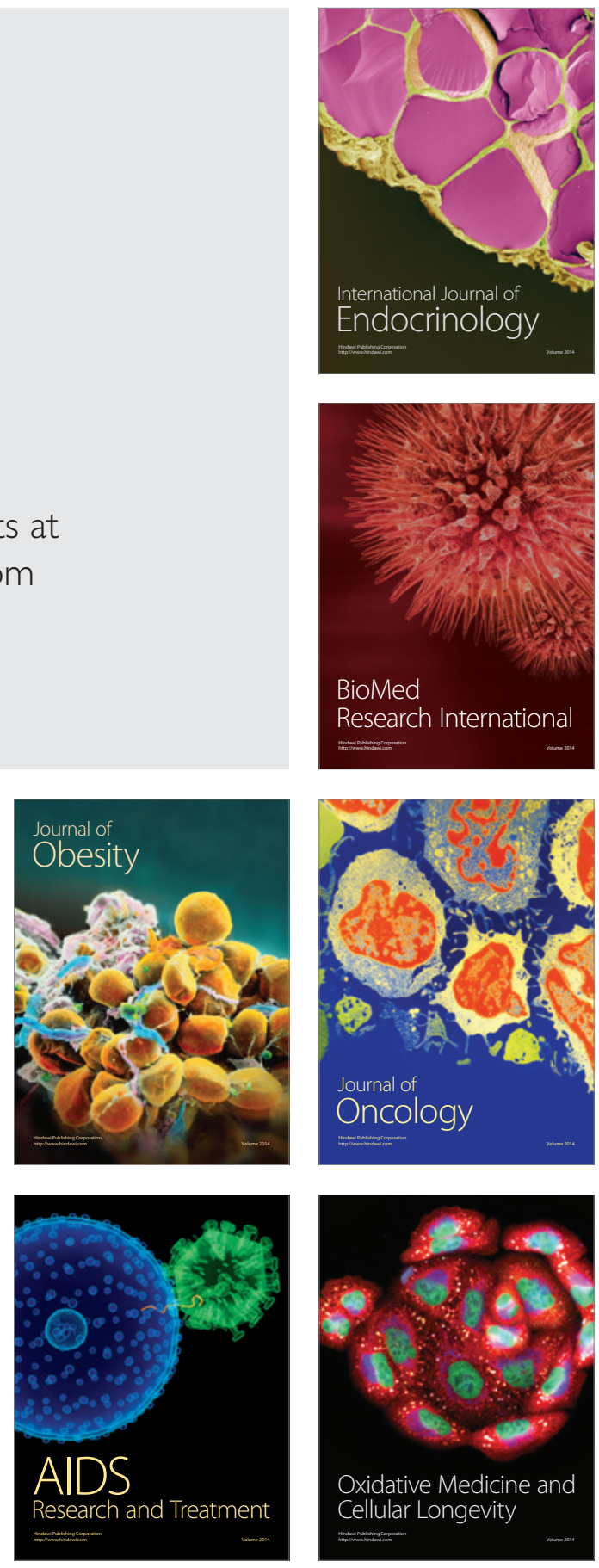